\title{
Current and future biomarkers for outcomes with immunotherapy in non-small cell lung cancer
}

\author{
Boris Duchemann $^{1,2,3 \#}$, Jordi Remon ${ }^{4 \#}$, Marie Naigeon ${ }^{1,2}$, Lydie Cassard ${ }^{1}$, Jean Mehdi Jouniaux ${ }^{1}$, \\ Lisa Boselli ${ }^{1}$, Jonathan Grivel ${ }^{1}$, Edouard Auclin ${ }^{5}$, Aude Desnoyer ${ }^{6,7}$, Benjamin Besse ${ }^{2,8}$, Nathalie Chaput ${ }^{1,6,7}$ \\ ${ }^{1}$ Gustave Roussy Cancer Campus, Laboratory of Immunomonitoring in Oncology, CNRS-UMS 3655 and INSERM-US23, Villejuif, France; \\ ${ }^{2}$ University Paris-Saclay, Faculty of Medicine, Le Kremlin Bicêtre, France; ${ }^{3}$ Medical and Thoracic Oncology Department, Hopital Avicenne, \\ AP-HP, Bobigny, France; ${ }^{4}$ Department of Medical Oncology, Centro Integral Oncológico Clara Campal (HM-CIOCC), Hospital HM Delfos, \\ HM Hospitales, Barcelona, Spain; ${ }^{5}$ Medical and Thoracic Oncology Department, Hôpital Européen Georges Pompidou, APHP, Paris, France; \\ ${ }^{6}$ University Paris-Saclay, Faculté de Pharmacie, Chatenay-Malabry, France; ${ }^{7}$ Laboratory of Genetic Instability and Oncogenesis, UMR CNRS 8200, \\ Gustave Roussy, Université Paris-Saclay, Villejuif, France; ${ }^{8}$ Cancer Medicine Department, Gustave Roussy, Villejuif, France \\ Contributions: (I) Conception and design: B Duchemann, J Remon, B Besse, N Chaput; (II) Administrative support: None; (III) Provision of study \\ materials or patients: None; (IV) Collection and assembly of data: None; (V) Data analysis and interpretation: None; (VI) Manuscript writing: All \\ authors; (VII) Final approval of manuscript: All authors. \\ \#These authors contributed equally to this work. \\ Correspondence to: Professor Nathalie Chaput. Gustave Roussy Cancer Campus, Laboratoire d'Immunomonitoring en Oncologie, 114 Rue Edouard \\ Vaillant, Villejuif F-94805, France. Email: nathalie.chaput@gustaveroussy.fr.
}

\begin{abstract}
Immune checkpoint inhibitors (ICI) have been validated as an effective new treatment strategy in several tumoral types including lung cancer. This remarkable shift in the therapeutic paradigm is in large part due to the duration of responses and long-term survival seen with ICI. However, despite this, the majority of cancer patients do not experience benefit from ICI. Even among patients who initially respond to ICI, disease progression may ultimately occur. Moreover, in some patients, these drugs may be associated with new patterns of progression such as pseudo-progression and hyper-progressive disease, and different toxicity profiles with immune-related adverse events. Therefore, the identification of predictive biomarkers may help to select those patients most likely to obtain a true benefit from these drugs, and avoid exposure to potential toxicity in patients who will not obtain clinical benefit, while also reducing the economic impact. In this review, we summarize current and promising potential predictive biomarkers of ICI in patients with nonsmall cell lung cancer (NSCLC), as well as pitfalls encountered with their use and areas of focus to optimize their routine clinical implementation.
\end{abstract}

Keywords: Biomarker; immune checkpoint inhibitor (ICI); immunotherapy; non-small cell lung cancer (NSCLC); liquid biopsy

Submitted Jul 10, 2020. Accepted for publication Aug 19, 2020.

doi: $10.21037 /$ tlcr-20-839

View this article at: http://dx.doi.org/10.21037/tlcr-20-839

\section{Introduction}

Programmed death-ligand 1 (PD-L1) expressed in tumor cells remains the only predictive biomarker used in daily clinical practice for patients with advanced non-small cell lung cancer (NSCLC). However, the tumoral heterogeneity of PD-L1 expression represents a bias that raises challenges for widespread use of this biomarker. Tumor mutational burden (TMB), defined as the number of somatic mutations contributing to the tumor's immunogenicity, has also been reported as a potential predictive biomarker. However, one of the major limitations for the use of biomarkers in NSCLC is the paucity of tumor tissue from biopsies (1), which severely limits the number and type of tests that 
can be performed, and alternative biomarkers and ways of evaluating biomarkers are actively being sought. Liquid biopsies, mainly dedicated to the analysis of circulating tumor DNA (ctDNA), are a novel non-invasive tool for genomic profiling and assessment of tumor heterogeneity in NSCLC (1). In this review we provide an overview of available biomarkers in NSCLC in tissue and liquid biopsies. We focus on tumor-related biomarkers, notably PD-L 1 and TMB, and also investigate biomarkers related to the tumor microenvironment (TME), notably tumor infiltrating lymphocytes (TILs), and host-derived biomarkers including circulating immune cells, soluble markers and the gut microbiome.

\section{Tumor-related biomarkers}

\section{PD-L1}

The increasing comprehension of the $\mathrm{PD}-1 / \mathrm{PD}-\mathrm{L} 1$ axis has been a major step in the development of tumoral immunotherapy. As more PD-(L)1 inhibitors are developed, the research focus has moved to identifying biomarkers for the activation of this axis, both in tumoral cells as well as immune cells and subsequently on any circulating counterparts (Figures 1,2).

\section{Tissue PD-L1}

The development of immune checkpoint inhibitor (ICI) targeting PD-(L)1 in NSCLC has been closely followed by the assessment of potential predictive biomarkers. $\mathrm{PD}-\mathrm{L} 1$ expression on tumor cells as determined by immunohistochemistry represents the most valuable and unique predictive biomarker in daily clinical practice. Response rates (RR) and outcome in terms of overall survival (OS) increase with higher PD-L1 expression (2-4). However various pitfalls remain, several of which have been thoroughly explored, notably PD-L1 tumoral expression, with technical issues related to the development of different monoclonal antibodies used for testing (5), differences in the choice of cut-off threshold, as well as a range of biological issues; these include the fact that PD-L1 is differentially expressed with inconsistent predictive values across tumor types (6) and furthermore that expression may be modulated during treatment (7). Moreover, the predictive value may depend on the mechanism of PD-L1 induction. Oncogenicaddicted NSCLC may cause an intrinsic elevation of PD-L1 expression and can be associated with a worse prognosis (8). On the other hand, extrinsic induction of PD-L1 by INF- $\gamma$ produced by lymphocytes seems to be associated with a favorable predictive value (9).

In the first-line treatment setting of advanced NSCLC patients, PD-L1 expression by immunohistochemistry on tumor cells has been widely used to select and stratify patients considered most likely to obtain benefit from ICI. However, not all pivotal trials have achieved a survival benefit with ICI compared with standard platinum-based chemotherapy (10-14). In contrast to nivolumab, which did not report an OS benefit $(10,11)$, atezolizumab (14) and pembrolizumab $(12,13)$ did, especially in tumors with high PD-L1 expression (12-14). These latter observations lead to FDA approval of pembrolizumab in tumors with PD-L1 $\geq 1 \%$ and atezolizumab in tumors with PD-L1 expression $\geq 50 \%$ in tumor cells, whereas the EMA only approved pembrolizumab as monotherapy in the first-line setting in tumors with PD-L1 expression $\geq 50 \%$. However, with the availability of more recent first-line data reporting the efficacy of ICI plus chemotherapy combination therapy compared with chemotherapy alone, the predictive value of PD-L1 expression appears diminished. These studies demonstrated that all patients derived a survival benefit with the combination compared to chemotherapy alone, regardless of PD-L1 expression and histologic subtype $(15-17)$. This led to FDA/EMA approval for ICI plus chemotherapy regardless of the level of PD-L1 expression. In the CheckMate 227 trial, nivolumab plus ipilimumab reported improvement in OS compared with chemotherapy in PD-L1 negative tumors [17.2 versus 12.2 months, HRT 0.64, 95\% confidence interval (CI): 0.51-0.81], however, efficacy of the combination in this subset of patients was only an exploratory analysis (18).

In PACIFIC trial, although durvalumab improved PFS and OS in PD-L1 $\geq 1 \%$ tumors, in 148 patients with PD-L1 $<1 \%$ tumors durvalumab neither improved PFS (HR 0.73; 95\% CI: 0.48-1.11) nor OS (HR: 1.14, 95\% CI: 0.71-1.84). Of note, efficacy of durvalumab in PD-L1 negative tumors was an exploratory post-boc analysis requested by EMA and the enrollment in the trial was not restricted to any threshold level for PD-L1 expression, and PD-L1 status was not mandatory for inclusion (19).

\section{Soluble PD-L1}

Surface molecules can assume two forms of expression, membrane-bound protein and a soluble form generated after proteolytic cleavage, such as is the case for the immune checkpoint molecules PD-1, PD-L1 and CTLA4. Elevated serum concentrations of the soluble forms 


\begin{tabular}{|c|c|c|c|c|c|c|c|}
\hline & \multicolumn{3}{|l|}{ Biomarker } & \multirow{2}{*}{$\begin{array}{l}\text { Method of detection } \\
\text { Immunohistochemistry }\end{array}$} & Tissue type & Association with positive predictive value & Level of evidence ${ }^{\star}$ and results \\
\hline \multirow[t]{9}{*}{ Tumor-related } & \multirow[t]{2}{*}{ PD-L1 pathway } & \multicolumn{2}{|c|}{ Tissue PD-L1 } & & Tumor & Positive PD-L1 tumor expression & Concordant results \\
\hline & & Soluble & & ELISA chemiluminescence & Blood & Conflicting results & Conflicting results \\
\hline & \multirow[t]{4}{*}{ Antigen recognition } & \multicolumn{2}{|c|}{ MSI-MDRD } & Immunohistochemistry & Tumor & Mismatch repair deficiency: hypermutator phenotypes & Concordant results \\
\hline & & TMB & Tumoral TMB & WES; NGS (Foundation One CDx TM and MSK-IMPACT) & Tumor & High mutational rate (tTMB $\geq 175$ mut/exome) & Conflicting results \\
\hline & & & Blood TMB & WES; NGS & Blood & High mutational rate & Conflicting results \\
\hline & & Tumor- & cific genotype & Direct sequencing; NGS & Tumor & Absence of EGFR, ALK or ROS1 mutations & Conflicting results \\
\hline & \multirow[t]{3}{*}{ Others } & CTC & & Enrichment (CellSearch') and detection (IF staining) & Blood & Low baseline CTC count & Results to be validated \\
\hline & & ctDNA & & $\begin{array}{l}\text { Multiplex targeted NGS; digital droplet PCR; RNASeq; } \\
\text { SNP array }\end{array}$ & Blood & $\begin{array}{l}\text { Undetectable ctDNA levels at week } 8 \text { of treatment; early } \\
\text { decrease in ctDNA burden at } 1 \text { month of treatment }\end{array}$ & y Concordant results \\
\hline & & \multicolumn{2}{|c|}{ Epigenetic } & $\begin{array}{l}\text { Bisulfite conversion of genomic DNA, whole-genome } \\
\text { amplification and array-based capture and scoring of } \\
\text { CpG loci }\end{array}$ & Tumor & EPIMMUNE signature & Results to be validated \\
\hline \multirow{2}{*}{$\begin{array}{l}\text { Tumor/host interaction: } \\
\text { microenvironment }\end{array}$} & \multicolumn{3}{|l|}{ TILs } & Immunohistochemistry; flow cytometry & Tumor & $\mathrm{CD}^{+} \mathrm{CD} 8^{+}$infiltration; TLLs density $>5 \%$ & Concordant results \\
\hline & \multicolumn{3}{|l|}{ B cells and TILs } & Immunohistochemistry; flow cytometry & Tumor & TLS presence & Results to be validated \\
\hline \multirow[t]{8}{*}{ Host-related } & \multicolumn{3}{|c|}{ Gene expression signature } & Microarray analysis & Tumor & IFN- $\gamma$ gene signature & Concordant results \\
\hline & \multirow[t]{2}{*}{$\begin{array}{l}\text { Circulating immune } \\
\text { cells }\end{array}$} & $\mathrm{e}^{\mathrm{CD} 3^{+} \mathrm{T}}$ & & Complete blood count; flow cytometry & Blood & $\begin{array}{l}\text { Expansion of } \mathrm{PD}-1^{+} \mathrm{CD} 8 \mathrm{~T} \text { cells during treatment; low } \\
\text { baseline proportion of } \mathrm{CD} 28^{-} \mathrm{CD} 57^{+} \mathrm{KLRG} 1^{+} \mathrm{CD} 8 \mathrm{~T} \text { cells }\end{array}$ & Results to be validated \\
\hline & & \multicolumn{2}{|c|}{ Neutrophils and MDSC } & Complete blood count; flow cytometry & Blood & $\begin{array}{l}\text { Low baseline proportion of circulating M-MDSCs; low } \\
\text { baseline dNLR }\end{array}$ & Results to be validated \\
\hline & \multirow{4}{*}{$\begin{array}{l}\text { Soluble systemic } \\
\text { immune or } \\
\text { inflammmatory } \\
\text { markers }\end{array}$} & \multicolumn{2}{|l|}{\begin{tabular}{|l|l|}
$\mathrm{LDH}$ \\
$\mathrm{CPD}$ \\
\end{tabular}} & Spectrophotometry & Blood & Low baseline LDH levels & Conflicting results \\
\hline & & CRP & & Immunoturbidimetry & Blood & Low baseline CRP levels & Results to be validated \\
\hline & & \multicolumn{2}{|c|}{ Albumin } & Immunoturbidimetry & Blood & High baseline albumin levels & Results to be validated \\
\hline & & Cytoki & & ELISA chemiluminescence & Blood & $\begin{array}{l}\text { Early decrease of IL-8 during treatment; increase of } \\
\text { TNF- } \alpha \text { and IFN- } \gamma \text { during treatment }\end{array}$ & Results to be validated \\
\hline & Microbiota & & & Bacterial 16 S ribosomal RNA gene sequencing & Gut microbiota & $\begin{array}{l}\text { High gut diversity at baseline } \\
\text { Akkermansia enrichment }\end{array}$ & Results to be validated \\
\hline & & ospectiv & idy 1 & Concordant re & & & \\
\hline & & trospect & study with indep & Conflicting result & & & \\
\hline & & trospect & study without a & Results to be val & dated in further s & tudies C & \\
\hline
\end{tabular}

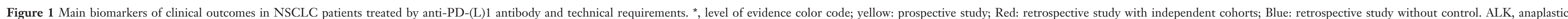

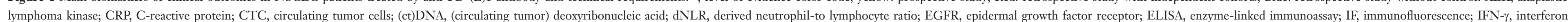

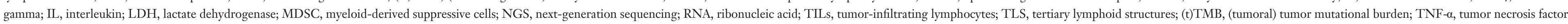
alpha; WES, whole exome sequencing. 


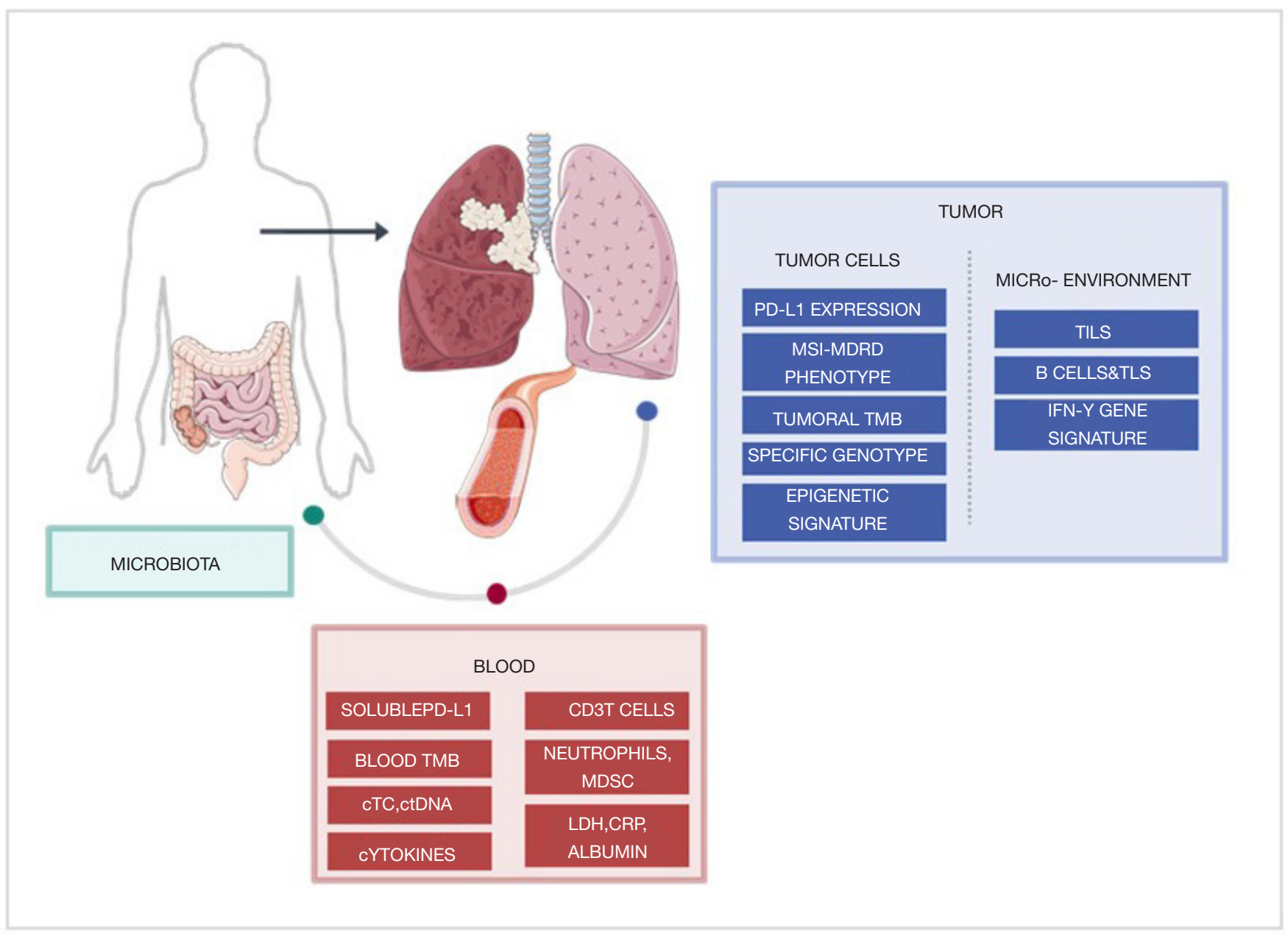

Figure 2 Main biomarkers of clinical outcomes in NSCLC patients treated by anti-PD-(L)1 antibody. CRP, C-reactive protein; CTC, circulating tumor cells; (ct)DNA, (circulating tumor) deoxyribonucleic acid; IFN- $\gamma$, interferon gamma; LDH, lactate dehydrogenase; MDSC, myeloid-derived suppressive cells; TILS, tumor-infiltrating lymphocytes; TLS, tertiary lymphoid structures; (t)TMB, (tumoral) tumor mutational burden.

of these three molecules (sPD-1, sPD-L, and sCTLA-4, respectively) were initially associated with autoimmune diseases (20) and are now being explored as predictive biomarkers in cancer (21).

In cultured cell lines, sPD-1 is produced by effector $\mathrm{T}$ cells and myeloid cells (22) and production of the soluble form is related to PD-L1 expression levels (23). Nevertheless, a correlation was not described between tumor PD-L1 expression (immunohistochemistry analysis on tumoral cells) and sPD-L1 levels (ELISA analysis) in patients with non-thoracic malignancies such as diffuse large B-cell lymphomas and renal cell carcinomas (24). These results hints at the preponderant role of the TME, including immune non-malignant cells, in sPD-L1 production $(24,25)$.

In advanced NSCLC patients, higher sPD-L1 or sPD-L2 expression was reported compared to healthy controls, and high sPD-L1 expression significantly correlated with worse prognosis (26-28), as has been reported in other malignancies $(29,30)$. In a recent study, the role of baseline and dynamic evolution of sPD-1 and sPD-L1 after two cycles of nivolumab were assayed in 51 advanced NSCLC patients (31). Positivity was defined as a plasma level above the lower limit of quantification $(0.156 \mathrm{ng} / \mathrm{mL})$. A composite criteria (sCombo) was defined by sPD-L1 and/or sPD-1 positivity. Score positivity at baseline was associated 
with shorter median progression-free survival [PFS; 78 days, 95\% CI: 55-109 versus 658 days, 95\% CI: 222-not reached; hazard ratio (HR) 4.12, 95\% CI: 1.95-8.71; $\mathrm{P}=0.0002]$ and $\mathrm{OS}$ (HR 3.99, 95\% CI: 1.63-9.80; $\mathrm{P}=0.003$ ). In multivariate analyses, score positivity remained significantly associated with shorter PFS (HR 2.66, 95\% CI: 1.17-6.08; $\mathrm{P}=0.02)$. Results from another NSCLC cohort treated with nivolumab support the negative prognostic impact of sPD-L1 plasma level at baseline under ICI (32). However, contradictory results have been published regarding the predictive value of dynamic sPD-L1 expression (25,31).

Several splicing variants have been described of sPD-L1, some of them lacking transmembrane domain. These variants may act as "decoys" of PD-L1 antibody in vitro and in animal model and may participate to PD-L1 antibody resistance (33).

Other potential sources of PD-L1 include exosomes which are small membrane vesicles (diameter, 50-100 $\mathrm{nm}$ ) with an endocytic origin, released by many cell types including $\mathrm{T}$ cells and dendritic cells. Tumor-derived exosomes contain substantial amounts of biologically active proteins, including immune checkpoint proteins (34). In patients with lung cancer, the amount of PD-L1 in these vesicles can impair immune functions. Adding patient PD$\mathrm{L}^{+}$exosomes to autologous lymphocytes can reduce in vitro cytokine production and induce $\mathrm{T}$ lymphocyte $\mathrm{CD} 8^{+}$ apoptosis (34). In a mouse xenograft model, exosomal PDL1 promoted a tumor immune escape mechanism that was abolished by PD1/PD-L1 blockers. Baseline exosomal PDL1 may also be used as a prognostic factor (35).

These results highlight that the PD-1/PD-L1 axis remains a cornerstone of $\mathrm{PD}(\mathrm{L}) 1$ inhibition biomarkers. To date, PD-L1 expressed by tumoral cells on a biopsy remains the only biomarker used in clinical practice in the context of administering ICI therapies. Nevertheless, it does not fully explain the sensitivity and resistance mechanisms to ICI, in particular for combination therapy. Circulating PD-L1 offers additional information, but prospective validation is warranted.

\section{MMRD and TMB}

Another major aspect of ICI response prediction is the ability of the immune system to detect specific tumoral antigens. ICI have met with success in tumor types with high mutational load including NSCLC, melanoma and tumors associated with DNA mismatch repair (MMR), suggesting the potential of mutational burden as a response biomarker. This led to the assessment of tumoral antigenicity, mainly via TMB evaluation in both tissue and blood samples (Figures 1,2).

\section{MSI and MMRD tumors}

DNA MMR is a system of recognition and repair of mutations arising during DNA replication. Mismatch repair deficiency (MMRD) has been associated with hypermutator phenotypes such as microsatellite instability (MSI) (36). This instability can lead to an increased TMB and high mutational load (36). Consequently, MSI and MMRD tumors are highly immunogenic and this has been used as a predictive biomarker for ICI outcome in clinical trials. These trials have consistently reported a highly favorable RR in several MSI-high (MSI-H) and MMRD tumor types $(37,38)$, leading to the first therapeutic agnostic approvals by the FDA in patients with unresectable or metastatic MSI-H or MMRD solid tumors, independent of the tumor localization. Nevertheless, this condition is rare in lung cancer $(<1 \%)$ (39). Some deleterious alterations of POLE, POLD1 and MSH2 genes have been found in patients with high TMB responding to ICI (40), however mutation signatures in lung cancer have been shown to be mostly associated with smoking habits (41).

Recently, DNA damage response and repair (DDR) gene alterations were reported in tumoral tissues of $50 \%$ of a cohort of NSCLC patients (42). Median TMB was significantly higher in the DDR-positive group compared to the DDR-negative group (12.1 versus $7.6 \mathrm{mut} / \mathrm{Mb}$, $\mathrm{P}<0.001)$, and DDR-positive tumors had a significantly higher RR (30.3\% versus $17.2 \%, \mathrm{P}=0.01$ ), longer median PFS (5.4 versus 2.2 months, HR: 0.58 , 95\% CI: 0.45-0.76, $\mathrm{P}<0.001)$, and longer median OS (18.8 versus 9.9 months, HR: $0.57,95 \%$ CI: $0.42-0.77, \mathrm{P}<0.001)$ with PD-(L)1 therapy, after adjusting for PD-L1, TMB, performance status, tobacco use, and line of therapy.

\section{Tumoral tissue and blood-based TMB}

Recent data suggest that TMB could be another predictor of ICI efficacy. TMB is calculated as the total number of non-synonymous somatic mutations of the genomics coding area. These mutations can lead to neoantigen formation and contribute to the immunogenicity of the tumor. The type of mutation may also contribute to the resulting antigenicity (43), with insertions and deletions leading to more antigen formation than non-synonymous single nucleotide variants. The TMB can be evaluated with various techniques (Whole exosome sequencing, Whole Genome Sequencing, Next 
Generation Sequencing), with different thresholds, and can be performed using tumor tissue (tTMB) or blood (bTMB). Data on their predictive value are conflicting, particularly in terms of ICI combinations and ICI chemotherapy combinations.

\section{Tumoral TMB}

The first-line trial CheckMate 026 compared nivolumab monotherapy versus chemotherapy in $\mathrm{PD}-\mathrm{L} 1 \geq 5 \%$ NSCLC. In exploratory subgroup analyses according to TMB, higher RR and longer PFS were reported with nivolumab compared with chemotherapy in tumors with high TMB (RR: $47 \%$ versus $28 \%$; PFS: 9.7 versus 5.8 months) (10). Of note, no difference in OS was found (18.3 versus 18.8 months). Following these results, the TMB was used prospectively as a biomarker for PFS as one of the two coprimary endpoints in the CheckMate 227 study. This study compared the combination of nivolumab and ipilimumab to platinum-based chemotherapy (44) in the first-line setting in advanced NSCLC. In the group of patients with $\geq 10 \mathrm{mut} / \mathrm{Mb}$ (high $\mathrm{tTMB} ; \mathrm{N}=299,17 \%$ of the randomized population), the combination arm reported a significant benefit compared with chemotherapy in PFS (7.2 versus 5.5 months, HR $0.58,75 \%$ CI: $0.41-0.81$ ) as well as an improvement in RR (45.3\% versus $26.9 \%$ ) (44). The coprimary endpoint of the study (OS in PD-L1 $\geq 1 \%$ ) was also met, with improved OS for the combination compared to chemotherapy (17.2 versus 12.2 months, HR $0.62 ; 95 \%$ CI: 0.48-0.78), leading to FDA approval of the nivolumab plus ipilimumab combination in the first-line setting in advanced NSCLC patients with PD-L1 $\geq 1 \%$. However, this HR benefit was subsequently shown to occur regardless of PD-L1 expression (PD-L1 $\geq 1 \%$; HR 0.79, 95\% CI: 0.650.96; and in PD-L1 <1\%; HR 0.62, 95\% CI: 0.49-0.79), or TMB level (high: HR 0.68, 95\% CI: $0.51-0.91$; or low: HR 0.75, 95\% CI: 0.59-0.94). Consequently, these results do not support tTMB as a predictive biomarker for ICI combination (11).

Similarly the efficacy of pembrolizumab plus platinumbased chemotherapy versus chemotherapy alone in the firstline setting for metastatic NSCLC, occurred regardless of tTMB status assessed by whole exome sequencing, and defining high $\mathrm{tTMB}$ as $\geq 175$ mut/exome (45). Therefore, randomized controlled trials have so far failed to show a survival benefit when stratifying patients by tTMB and these data do not currently support the prognostic or predictive value of $\mathrm{tTMB}$ in NSCLC patients.

\section{Blood-based TMB}

First-line $\mathrm{t} T \mathrm{MB}$ can be challenging to obtain, and use of blood-based TMB (bTMB) is increasing, with several studies suggesting its predictive role. The OAK and POPLAR studies comparing ICI versus chemotherapy in the second-line setting (46), used several bTMB cutoff points $\geq 10, \geq 16$, and $\geq 20 \mathrm{mut} / \mathrm{Mb}$, and blood-based approaches (measured by the Foundation Medicine assay) to assess TMB. Both studies reported an inverse relationship between TMB and OS HR, suggesting that BTMB may predict benefit of atezolizumab as second-line therapy in NSCLC (47).

In the first-line setting, the MYSTIC trial assessed the efficacy of a durvalumab plus tremelimumab combination or durvalumab monotherapy compared with platinumbased chemotherapy in a PD-L1 expressing population (PDL-1 $\geq 25 \%$ ). This study did not meet any of the three primary endpoints: PFS and OS for the immunotherapy combination compared to chemotherapy and OS for durvalumab compared to chemotherapy. However in a retrospective exploratory analysis, patients with high bTMB [ $\geq 16 \mathrm{mut} / \mathrm{Mb}(48)$ or $\geq 20 \mathrm{mut} / \mathrm{Mb}$ ] derived a survival benefit with combined durvalumab plus tremelimumab compared with chemotherapy (49). Similarly, the nonrandomized phase II B-F1RST study evaluated bTMB as a predictive biomarker for atezolizumab according to a cutoff of $16 \mathrm{mut} / \mathrm{Mb}$. Atezolizumab achieved longer PFS (5.0 versus 3.5 months, HR $0.80,90 \%$ CI: $0.54-1.18$ ) and OS (23.9 versus 13.4 months, HR $0.66,90 \%$ CI: $0.40-1.10$ ) in tumors with $\mathrm{bTMB} \geq 16 \mathrm{mut} / \mathrm{Mb}$ versus $<16 \mathrm{mut} / \mathrm{Mb}$, respectively. These results suggest a clinical benefit, albeit not statistically significant, of atezolizumab in tumors with high bTMB (50). The ongoing phase III BFAST trial evaluating different ICIs according to bTMB in metastatic NSCLC (NCT03178552) is designed to address this question.

Similarly, in another retrospective study with 66 advanced NSLCL, first-line treatment with pembrolizumab either alone or in combination with chemotherapy achieved longer PFS in patients with $\mathrm{bTMB} \geq 16 \mathrm{mut} / \mathrm{Mb}$ than in those with $\mathrm{bTMB}<16$ mut/Mb (14.1 versus 4.7 months; HR 0.30, 95\% CI: $0.16-0.60 ; \mathrm{P}<0.001)$. Median OS for patients with $\mathrm{bTMB} \geq 16 \mathrm{mut} / \mathrm{Mb}$ was not reached versus 8.8 months for patients with bTMB $<16$ mut/Mb (HR 0.48 , 95\% CI: $0.22-1.03 ; \mathrm{P}=0.061)$. However, the predictive role of bTMB did not apply for patients with co-mutations in STK11/KEAP1/PTEN and ERBB2 (51). 
On the other hand, the phase III NEPTUNE trial (NCT02542293) comparing durvalumab and tremelimumab versus platinum-based chemotherapy in the first-line treatment did not met the OS endpoint in patients with a high bTMB ( $\geq 20 \mathrm{mut} / \mathrm{Mb})$ (52).

To date, the prognostic and predictive value of $\mathrm{tTMB}$ or bTMB remains a challenge, mainly due to the absence of uniform standards for the cut-off point for defining high TMB, sample type and the technical platform used to evaluate it. Data from prospective trials are warranted to more accurately identify the predictive and/or prognostic value of TMB for benefit.

\section{Specific tumor mutations and circulating DNA}

Along with TMB, the tumoral genome has further potential to be used as a predictive marker. Specific tumor genotypes such as oncogene addicted or LKB1/STK11 mutated tumors have been hypothesized to be associated with primary resistance ICI. Moreover, direct evaluation of tumoral cell DNA and circulating DNA have also been investigated as possible circulating biomarkers (Figures 1,2).

\section{Tumor-specific genotype}

Some genomic alterations have been correlated with lack of efficacy of ICI. In a multicentric international retrospective cohort of 551 oncogenic addicted NSCLC patients (IMMUNOTARGET), objective RRs according to driver alterations following anti-PD(L)-1 treatment were KRAS 26\%, BRAF 24\% ROS1 17\%, MET 16\%, EGFR 12\%, HER2 7\%, RET 6\%, and ALK 0\% (8). Median PFS in the overall cohort was 2.8 months. However, in another retrospective study ( $\mathrm{N}=107)$, the RRs were $26 \%$ for BRAF-V600, 33\% for BRAF-nonV600, 27\% HER2, 38\% $M E T$ and $38 \%$ RET-altered, similar to outcomes reported in wild-type NSCLC patients (53).

Somatic mutations and co-mutations have also been associated with specific type of TME and ICI resistance, such as is the case for inactivating LKB1/STK11 genomic alterations. These alterations are present in $~ 25 \%$ of KRASmutant adenocarcinomas and are frequently associated with a "cold", non-T cell-inflamed microenvironment with a paucity of infiltrating $\mathrm{CD}^{+}, \mathrm{CD}^{+}{ }^{+}$and $\mathrm{CD} 8^{+}$ $\mathrm{T}$ cells and low tumor cell expression of PD-L1. KEAP1 is also associated with a cold micro-environment in particular when it is associated with a PTEN mutation (54). Furthermore, co-mutations in either LKB1/STK11 or
KEAP1 were associated with worse clinical outcomes with chemoimmunotherapy using pemetrexed-carboplatin (or cisplatin) plus the anti-PD-1 antibody pembrolizumab in non-squamous NSCLC (55). Similarly, in the MYSTIC trial, the occurrence of $L K B 1 / S T K 11$ or KEAP1 mutations correlated with poorer PFS and OS across treatment arms compared with wild-type counterparts (56). In contrast, an exploratory analysis of the phase III KEYNOTE 042 trial (pembrolizumab versus chemotherapy in the firstline setting of PD-L1 $\geq 1 \%$ advanced NSCLC patients) the occurrence of KEAP1 or LKB1/STK11 mutation (34\% of the whole population) did not affect the efficacy of pembrolizumab (RR 31\%, OS 18 months) (57). However, the sample size of this study is too small to impact daily clinical practice with ICI as monotherapy as the standard treatment in this population with these co-mutations, and further formal analyses are warranted.

\section{Circulating tumor cells (CTC) and circulating-tumor DNA}

To overcome the difficulties associated with obtaining tissue, non-invasive methods have been developed in the search for ICI biomarkers, including analysis of CTC and ctDNA in NSCLC. CTC and ctDNA have been used for assessing PDL1 status $(58,59)$ and as dynamic biomarkers of ICI efficacy (59-61). In NSCLC patients, obtaining ctDNA clearance at one (62) or two months (63) after ICI initiation has been found to correlate with a prolonged duration of response. In contrast, an increase in ctDNA $>20 \%$ at 6 weeks after nivolumab was associated with a worse outcome (63). PD-L1 can be assessed on CTCs, however sensitivity ranges from $45 \%$ (59) to $93 \%$ (58) of samples. To date, no prospective trial has confirmed PD-L1 expression on CTCs as a predictive biomarker of ICI efficacy $(58,59,64-66)$. On the contrary, some studies suggest that high PD-L1 expression on CTCs at baseline was associated with a poor outcome in patients treated with anti-PD(L)1 (58). Moreover, PD-L1 ${ }^{+}$ CTC increases at progression, possibly predicting resistance to ICI (65). Finally, logistically, cost and turnaround time of these analyses are critical and may limit the clinical applicability of CTC analyses.

\section{Epigenetic biomarkers}

DNA methylation is an epigenetic chemical "flag" which is critical for several cellular activities and is often altered in human diseases including cancer. A DNA methylation 
profile signature was generated in a discovery cohort of 34 NSCLC patients treated with ICI (EPIMMUNE) (67). This signature was associated with an improved outcome (PFS, $\mathrm{P}=0.0067$; OS, $\mathrm{P}=0.0012$ ), and was confirmed in an EPIMMUNE validation cohort with 47 patients. This methylation involves forkhead box P1 (FOXP1), and the unmethylated status of this single gene was confirmed as a predictive positive biomarker for PFS (HR 0.415, $\mathrm{P}=0.006$ ) and OS (HR 0.409, 95\% CI: 0.22-0.78; $\mathrm{P}=0.009$ ) in a third cohort. The EPIMMUNE-positive signature was not associated with PD-L1 expression, the presence of CD8 ${ }^{+}$ cells, or mutational load. Moreover, this study associated the signature status with tumoral inflammatory infiltration.

\section{Tumor-host interaction: Micro-environment biomarkers}

The TME is composed of immune cells, fibroblasts, and vascular and lymphatic tissues surrounding the tumoral cells. This microenvironment is constantly evolving, dependent on signaling molecules, with the cancer cells promoting immune evasion on the one hand and the host controlling tumoral proliferation on the other $(68,69)$. Within the TME, several kinds of host immune cells can be recruited from adaptative cells (such as B and T lymphocytes) and innate immunity (such as polymorphonuclear leukocytes and Natural killer). The functional orientation of the immune population has been described as being dependent on the local immune contexture (70). It has been associated with patient outcomes in multiple tumor types and has been explored for its predictive potential when using ICI. Despite being more difficult to assess in clinical practice, mainly due to a lack of access to sufficient tissue samples, understanding the microenvironment is likely to be critical to deciphering the mechanism of immunotherapy (71) (Figures 1,2).

\section{TILs}

TILs have been correlated with improved survival in several cancer types including NSCLC (72). High levels of TILs, in particular CD8-positive TILs, correlate with improved survival probably reflecting a greater immune tumoral recognition by the immune system (73). This inflamed, 'hot tumor' phenotype, may have predictive value during ICI treatment (74). Exploratory studies have confirmed the potential interest of $\mathrm{CD} 8^{+}$infiltrate as a biomarker in several conditions. The immune infiltrate and PD-L1 tumoral expression was associated with response to nivolumab in 65 advanced lung cancer patients (75). In another study enrolling 98 patients with advanced NSCLC, TIL density $>5 \%$ correlated with PFS (HR 0.31, CI: 0.14-0.68, $\mathrm{P}=0.004$ ) and higher objective RR (OR $=3.5,95 \% \mathrm{CI}, 1.06-11.7$, $\mathrm{P}=0.04$ ) in a multivariate analysis (76). The nature of the $\mathrm{T}$ cell infiltrate may also predict therapeutic outcome with ICI. Anagnostou et al. described the oligoclonal expansion of pre-existing intratumoral T-cell clones in patients with tumoral response to ICI (61). Functionality and specific TIL phenotypes have been associated with response, such as high CD3 expression, T cell low granzyme B and low Ki-67 levels, proposed to be a "dormant" phenotype and associated with a better outcome (77).

\section{B cells and tertiary lymphoid structures (TLS)}

Recent studies suggest a role for B cells when localized to tumor compartments called TLS. TLS are aggregates of immune cells in response to immunological stimuli in the presence of B cells (78). TLS, like TILs, are considered to be a predictor of increased survival (79). This role may be related to $\mathrm{B}$ cell activation, antibody cell death, and cooperation with T cells. Apparition of TLS during treatment in various tumor types appears to be associated with favorable evolution during ICI treatment (80-82), although this is yet to be evaluated in lung cancer.

Several other microenvironment parameters including hypoxia, angiogenesis and the extracellular matrix are under exploration. To be successful, these parameters must be correlated with biological or radiological surrogates and may be candidates to be combined with existing biomarkers (71).

\section{Gene expression signature}

Multiple-gene signatures may have prognostic value in NSCLC (83). Nevertheless, limited data exist about the predictive role of immune gene signatures in NSCLC tumors treated with ICI. These signatures are mostly related to IFNg signaling. In several malignancies, the baseline IFNg mRNA signature had predictive role for RR and PFS with pembrolizumab (84). In NSCLC, PD-1 gene expression along with a 12 -gene signature tracking CD8, CD4 T-cell, natural killer cells, and IFN activation was associated with nonprogressive disease and PFS (85). In the POPLAR trial comparing docetaxel to atezolizumab 
in second-line advanced NSCLC patients, tumors with high expression of the T-effector-associated and IFN$\gamma$-associated gene signature demonstrated improved OS (HR, 0.43; 95\% CI, 0.24-0.77) (86). In another study in 17 patients with NSCLC treated with nivolumab, mRNA expression levels (divided in tertile, high if superior to the $1^{\text {st }}$ tertile) were explored in tumoral samples. The only mRNA associated with PFS was IFNg (5.1 versus 2.0 months, HR 6.66; 95\% CI: $1.2-36.8, \mathrm{P}=0.0297$, for high and low expression respectively) (87).

\section{Host related biomarkers: functional status of the immune system}

\section{Circulating immune cells}

Circulating blood cells populations, including immune cells subpopulations may reflect host immune system functionality (Figures 1,2). Baseline and on-treatment variations in these populations have frequently been associated with cancer outcomes. Different techniques are available, some robust and clinically validated such as complete blood counts (CBC) and others more specific with subpopulation analysis using flow cytometry immunophenotyping. One strength of using fresh immune cell whole blood real-time monitoring, is that it allows more reliable data to be obtained for some brittle immune cell populations. Comparative studies with frozen peripheral blood mononuclear cells (PBMC) and fresh whole blood identified that some populations could be detected with the same sensitivity, while others may not be consistently determined from frozen PBMC. For example, for some memory $\mathrm{T}$ cell populations (using CD45RA and/or CD62L and/or CCR7 staining), regulatory $\mathrm{T}$ cells (Treg) seemed to be underestimated in PBMCs, with a large variability of $20 \%$ to $30 \%$. In addition, neutrophils, the main subpopulation of leucocytes, cannot be recovered from frozen PBMCs (88).

\section{Blood $\mathrm{CD}^{+}$T lymphocytes}

Lymphocyte functional status, e.g., activation, senescence or polarization can be studied on circulating $\mathrm{T}$ lymphocytes and some populations have been investigated as biomarkers with ICI treatment. In NSCLC patients, PD- $1^{+} \mathrm{T}$ cells are more frequent than in healthy controls $(27,89)$ and are associated with a worse clinical outcome. In a study by Zheng et al. including 42 NSCLC patients, median OS and
PFS were shorter in patients with high expression of PD$1^{+} \mathrm{CD} 4^{+}$circulating $\mathrm{T}$ cells (89). In another study, other checkpoint inhibitor molecules including PD-1, PD-L1 and PD-L2 on PBMC correlated with a worse prognosis. Among 70 patients who did not receive ICI, PD-L1 expression on $\mathrm{CD}^{+}$and $\mathrm{PD}-1$ expression on $\mathrm{CD}^{+} \mathrm{T}$ cells were associated with poor outcome (27).

Evolution and proliferation of these populations can also be used for predicting ICI efficacy. Kamphorst et al. reported the dynamic evolution of immune checkpoints on T cells in a cohort of 29 NSCLC patients treated with ICI. An increase in proliferation of circulating $\mathrm{PD}-1^{+} \mathrm{CD} 8^{+}$ $\mathrm{T}$ cells within four weeks after treatment initiation was associated with better outcome (90). The phenotype of these cells has been elucidated with an effector phenotype $\left(\mathrm{HLA}_{-} \mathrm{DR}^{+}, \mathrm{CD} 38^{+}, \mathrm{Bcl}-2^{\text {low }}\right)$, associated with expression of co-stimulatory molecules (CD28, CD27, ICOS) as well as high expression of CTLA-4. Early proliferation of PD-1 CD8 $T$ cells after PD-1 infusion was observed in more than three-quarters $(78.5 \%)$ of patients who experienced clinical benefit versus only $21.5 \%$ of patients with progressive disease (90).

Another study associated the proliferative response of peripheral $\mathrm{PD}-1^{+} \mathrm{CD} 8^{+} \mathrm{T}$ cells after 1 week of anti-PD- 1 therapy with a positive outcome in patients with NSCLC (91). $\mathrm{Ki}-67_{\mathrm{D} 7 / \mathrm{D} 0}$ was tested as a predictive biomarker in patients with NSCLC $(\mathrm{N}=79)$ or thymic epithelial tumors $(\mathrm{N}=31)$. These $\mathrm{T}$ cells were found to have proliferated seven days after ICI with a reduction after three weeks (91). The cut-off was optimized to 2.8 for $\mathrm{Ki}-67_{\mathrm{D} 7 \mathrm{DD} 0}$ with a higher probability of clinical benefit in patients with Ki-67 $7_{\mathrm{D} 7 / \mathrm{D} 0} \geq 2.8$ than in patients with $\mathrm{Ki}-67_{\mathrm{D} 7 \mathrm{D} 0}<2.8(\mathrm{P}<0.001)$. The same trend was found with PFS, which was 8.7 months (95\% CI: 4.3-13.2 months) in patients with Ki-67 $7_{\mathrm{D} 7 / \mathrm{D} 0} \geq 2.8$ and 3.9 months $(95 \%$ CI: 1.2-6.6 months) in those with Ki-67 $\mathrm{D} 7 / \mathrm{D} 0<2.8(\mathrm{P}=0.027)$, without modification of its predictive value when adding a score using tumoral PD-L1 expression (91).

$\mathrm{T}$ cell differentiation phenotypes have also been explored as a biomarker for ICI treatment. Patients with metastatic NSCLC express more memory effectors and fewer naïve T cells than control patients (92). In a cohort of 22 NSCLC patients, central memory (CM) to effector memory (EM) T cell ratio (TCM/TEM) was correlated with response during ICI treatment (92), as well as with longer PFS. It was also associated with high PD-L1 expression in the tumor and an increased inflammatory signature. In another cohort $(\mathrm{N}=51)$, the level of baseline functional $\mathrm{CD}^{+}$memory $\mathrm{T}$ cells, in 
particular those with low co-expression of PD-1/LAG-3, were associated with response under ICI (93).

Immunosenescence is another phenotype related to chronic antigenic stimulation. T cell senescence reflects a terminal differentiation status of a $\mathrm{T}$ cell with low proliferative activity, an oligoclonal $\mathrm{T}$ cell receptor repertoire, and reduced capacity to recognize antigenic diversity (94). Senescent and exhausted T-cells share some characteristics, however senescent cells conserved their cytotoxic potential (95). Blood senescent T cells, defined as $\mathrm{CD} 3^{+} \mathrm{CD} 8^{+} \mathrm{CD} 28^{\text {neg }} \mathrm{CD} 57^{+} \mathrm{KLRG} 1^{+}$, have recently been studied in patients with advanced NSCLC treated with ICI (96). Senescent populations were more frequent in NSCLC patients and in patients receiving chemotherapy compared to treatment-naïve patients (97). In a recent preliminary study, 43 ICI treated patients were evaluated for $\mathrm{T}$ cell senescence. Patients presenting a high proportion of senescent $\mathrm{CD}^{+} \mathrm{T}$ cells had significantly lower RR (31\% versus $0 \%, \mathrm{P}=0.03)$, disease control rate $(81 \%$ versus $29 \%$, $\mathrm{P}=0.002)$, PFS [7.3 months, 95\% CI: 2.7-non reached (NR) versus 1.8 months, 95\% CI: $1.3-\mathrm{NR} ; \mathrm{P}=0.02]$ and $\mathrm{OS}$ (NR, 95\% CI: 6.04-NR, versus 2.6 months, 95\% CI: $1.9-$ $\mathrm{NR} ; \mathrm{P}=0.01$ ). Interestingly senescent $\mathrm{CD} 8^{+} \mathrm{T}$ cells were not associated with clinical outcome in a cohort of patients treated with chemotherapy.

$\mathrm{CD}^{+}$cells are major but heterogenous effectors of antitumoral immunity. Deciphering T cell subpopulations such as senescent, central memory or activated $\mathrm{PD} 1^{+}$ may provide a better understanding of immunotherapy mechanisms and predictive tools, however this requires confirmation in independent cohorts.

\section{Circulating neutrophils and myeloid-derived suppressive cells (MDSC)}

An association between neutrophils and poor prognosis has been suspected in several cancer types for some time. Recent literature indicates that tumors may play a role in early differentiation of neutrophils by creating various phenotypic and functional polarization states able to influence tumor development. In solid tumors, neutrophils can be found both in the TME and the blood, and are generally associated with a poor prognosis (98). Neutrophils dominate the NSCLC immune landscape with a mostly immune suppressive role (99). Recently we demonstrated that some circulating innate immune markers including neutrophils were related to prognosis in advanced NSCLC patients (100). Neutrophils increase may be mostly related to granulocyte colony-stimulating factor production by the tumor (101). Several ratios have been evaluated as potential biomarkers, including neutrophil to lymphocyte ratio (NLR; neutrophils/lymphocytes) and derived neutrophil to lymphocyte ratio [dNLR: (neutrophils)/(leucocytesneutrophils)] (98). In a large meta-analysis including over 40,000 patients, NLR >4 was associated with worse OS, cancer-specific survival, PFS and disease-free survival in all types and stage of cancers (102). However, the threshold of these ratios has not been homogenously determined across published reports and these studies were mainly conducted in the pre-ICI area.

We previously evaluated the combined dNLR and lactate dehydrogenase $(\mathrm{LDH})$ level as the lung immune prognostic index (LIPI) in advanced NSCLC patients treated with immunotherapy. Patients with high baseline dNLR $(>3)$ and LDH (above the upper limit of normal) were associated with worse prognosis for ICI treatment $(\mathrm{N}=466)$, but not with chemotherapy ( $\mathrm{N}=152)$ (103). Nonetheless, the prognostic value of NLR and LIPI in NSCLC patients treated with ICI remains uncertain. In two recent pooled cohorts from clinical trials enrolling 1,489 (104) and 2,440 patients (105), treated with ICI or chemotherapy, a good LIPI score was associated with better OS both in patients receiving ICIs and in those receiving chemotherapy. Questions remain over differences in the magnitude of the benefit for patients treated with immunotherapy (106), and the role of the LIPI score warrants evaluation in prospective trial. Dynamic evolution of the LIPI score during treatment with ICI has also been correlated as a prognostic factor (107).

Other immunoregulatory cells can be recruited during chronic inflammatory processes such as MDSC. This cell population is more frequent in patients with lung cancer than in healthy volunteers (108) and has been associated with worse prognosis (109). It is a heterogeneous population and can be mainly divided into two groups, neutrophil-like (g-MDSC or PMN-MDSC) and monocyte-like (M-MDSC) (108,110-112). Increased levels of M-MDSCs have been correlated with worse PFS following chemotherapy (3 versus 9 months, $\mathrm{P}<0.01)(113)$ and $\mathrm{RR}(\mathrm{P}=0.02)(114)$.

Concerning ICI treatment, a recent study in two prospective cohorts including 63 patients evaluated the role of Lox-1 $1^{+}$PMN-MDSC and Treg cells (115). No difference between responders and progressors was found at baseline, however after a single nivolumab administration, Lox$1^{+}$PMN-MDSC diminished in responding patients. An 
inverse correlation was observed for Tregs. The elevation of the Treg to Lox- $1^{+}$PMN-MDSCs ratio (TRM ratio, cutoff 0.39 ) was associated with longer median PFS (103 versus 35 days; $\mathrm{P}=0.0079$ ) than in patients with low TRM. We consider that PMN-MDSC proliferation and recruitment in non-responders after anti-PD-1 therapy might impair its efficacy (115).

\section{Soluble systemic markers: LDH, CRP, albumin and otber inflammatory proteins}

Systemic nonspecific inflammation or metabolic shifts may be involved in immune-resistance mechanisms during cancer development. Some generic blood tests, many of which are validated in daily practice, have been investigated as potential inflammatory biomarkers in cancer patients.

Glucose metabolism is impaired in cancer cells with predominant glycolysis despite aerobic conditions (known as the Warburg effect). This allows rapid proliferation but requires upregulation of most enzymes involved in the glycolytic pathway, including LDH. LDH elevations had already been associated with an adverse prognosis in several studies before the emergence of ICI, in several types of solid tumors (116), including thoracic malignancies (117). The question of the predictive role of LDH during ICI treatment has previously been evoked; in a meta-analysis with advanced NSCLC patients treated with ICI, high pretreatment LDH levels (above the upper limit of normal) were significantly correlated with shorter PFS (HR 1.62, 95\% CI: $1.26-2.08, \mathrm{P}<0.001)$ and OS (HR 2.38, 95\% CI: $1.37-4.12, \mathrm{P}=0.002)(118)$.

Systemic inflammation and nutritional status biomarkers have been investigated regarding ICI efficacy, likely with less specificity but wide availability in routine practice. Retrospective studies have shown that C-reactive protein (CRP) elevation has been associated with worst prognosis in NSCLC and other malignancies $(119,120)$. Consistently, in the non-randomized prospective B-F1RST trial evaluating atezolizumab monotherapy in advanced NSCLC, a decrease in serum CRP over six weeks was associated with PFS and OS benefits (50). Poor nutritional status with decreased albumin has been correlated with poor response to ICI, again in a retrospective study (121). Concerning cytokines, several interleukins have been associated with the disease course. In NSCLC, the dynamic evolution of IL-8 during ICI treatment was reported as a biomarker, with a benefit for patients with early decreases of IL-8 levels (122). In others studies, an increase of tumor necrosis factor and INF- $\gamma$ during ICI therapy correlated with better outcome $(25,123)$.

\section{Gut microbiome}

The gut microbiome has been the subject of considerable interest during the last decade. It is suspected of playing a critical role in the maturation and education of the immune system at the basal state as well as during carcinogenesis with an inflammation induced by bacteria. Most studies have been conducted in metastatic melanoma patients with reports of enrichment of a given bacterial subpopulation [e.g., Bifidobacterium (124), or Ruminococcaceae (125)] or higher diversity (125) associated with response. In NSCLC patients under ICI, responders to nivolumab had higher gut diversity at baseline with a stable composition during treatment (126). Evolution under ICI has been correlated with specific microbiota compositions; a study in 60 NSCLC patients showed an enrichment of Akkermansia muciniphila at cancer diagnosis on responders (69\%) compared to $34 \%$ on responders, and correlation with TH1 cytokine polarization (127). Microbiota diversity can also be affected the by antibiotics and may have an impact on ICI therapy (128). While these results are interesting, confirmation in a prospective trial is currently ongoing.

\section{Conclusions}

To date, most $\mathrm{PD}(\mathrm{L}) 1$ inhibition strategies in NSCLC have been based on PD-L1 expression on tumor cells. Other promising biomarkers such as TMB have not been adopted in routine clinical use, mainly due to the difficulty of differentiating between their prognostic versus their predictive value as well as technical or logistical global coherence in terms of methodology and thresholds. Several host-related or microenvironment-based biomarkers have recently been uncovered and deserve validation in independent cohorts in particular tumoral epigenetic signature and circulating immune cells subpopulation. All these biomarkers provide insight into the complexity of the antitumoral immune response. In the next few years, the challenge will likely be how to combine these predictive factors to accurately predict the response to ICI and personalize the choice of combination therapy.

\section{Acknowledgments}

Sarah MacKenzie providing writing assistance. 
Funding: This study was supported by by Gustave Roussy Cancer Campus, Fondation Gustave Roussy, the Institut National de la Santé et de la Recherche Médicale (INSERM), the Centre National de la Recherche Scientifique (CNRS), SIRIC SOCRATE 2.0 (INCaDGOS-INSERM_12551); Direction General de l'Offre de Soins (DGOS; TRANSLA 12-174). Dr. Boris Duchemann was financed by AP-HP.

\section{Footnote}

Provenance and Peer Review: This article was commissioned by the Guest Editors (Jordi Remon and Benjamin Besse) for the series "Immunotherapy in other thoracic malignancies and uncommon populations" published in Translational Lung Cancer Research. The article has undergone external peer review.

Conflicts of Interest: All authors have completed the ICMJE uniform disclosure form (available at http://dx.doi. org/10.21037/tlcr-20-839). The series "Immunotherapy in other thoracic malignancies and uncommon populations" was commissioned by the editorial office without any funding or sponsorship. JR served as the unpaid Guest Editor of the focused issue and serves as an unpaid editorial board member of Translational Lung Cancer Research from Sep. 2019 to Sep. 2021. BB served as the unpaid Guest Editor of the focused issue. BD reports personal fees and non-financial support from Roche, non-financial support from Oxyvie, personal fees from Pfizer, non-financial support from Astra Zeneca, outside the submitted work. JR reports ADVISORY from MSD, ADVISORY from BOEHRINGER, SPEAKER from PFIZER, personal fees and TRAVEL from OSE IMMUNOTHERAPEUTICS, TRAVEL/ADVISORY from BMS, TRAVEL/ADVISORY from ASTRAZENECA, TRAVEL/ADVISORY from ROCHE, outside the submitted work. EA reports nonfinancial support from Travel expenses: Mundipharma, personal fees from Sanofi Genzyme, outside the submitted work. BB reports grants from Abbvie, grants from Amgen, grants from Astrazeneca, grants from BeiGene, grants from Blueprint Medicine, grants from BMS, grants from Boehringer Ingelheim, grants from Celgene, grants from Cristal Therapeutics, grants from Daiichi-Sankyo, grants from Eli Lilly, grants from GSK, grants from Ignyta, grants from IPSEN, grants from Inivata, grants from Janssen, grants from Merck KGaA, grants from MSD, grants from Nektar, grants from Onxeo, grants from
OSE immunotherapeutics, grants from Pfizer, grants from Pharma Mar, grants from Roche Genentech, grants from Sanofi, grants from Servier, grants from Spectrum Phamarceuticals, grants from Takeda, grants from Tiziana Pharma, grants from Tolero Pharmaceuticals, outside the submitted work. NC reports grants from BMS Fondation, during the conduct of the study; grants from SANOFI, grants from GSK, grants and personal fees from ASTRAZENECA, grants from ROCHE, grants and other from CYTUNE PHARMA, grants from BMS Fondation, outside the submitted work. The authors have no other conflicts of interest to declare.

Ethical Statement: The authors are accountable for all aspects of the work in ensuring that questions related to the accuracy or integrity of any part of the work are appropriately investigated and resolved.

Open Access Statement: This is an Open Access article distributed in accordance with the Creative Commons Attribution-NonCommercial-NoDerivs 4.0 International License (CC BY-NC-ND 4.0), which permits the noncommercial replication and distribution of the article with the strict proviso that no changes or edits are made and the original work is properly cited (including links to both the formal publication through the relevant DOI and the license). See: https://creativecommons.org/licenses/by-nc-nd/4.0/.

\section{References}

1. Friedlaender A, Nouspikel T, Christinat Y, et al. TissuePlasma TMB Comparison and Plasma TMB Monitoring in Patients With Metastatic Non-small Cell Lung Cancer Receiving Immune Checkpoint Inhibitors. Front Oncol 2020;10:142.

2. Brahmer J, Horn L, Hossein B, et al. Long-term Survival Outcomes with Nivolumab (NIVO) in Pts with Previously Treated Advanced Non-Small Cell Lung Cancer (NSCLC): Impact of Early Disease Control and Response. J Thorac Oncol 2019;14:S1152-3.

3. Herbst RS, Garon EB, Kim DW, et al. Long-Term Outcomes and Retreatment Among Patients With Previously Treated, Programmed Death-Ligand 1-Positive, Advanced Non-Small-Cell Lung Cancer in the KEYNOTE-010 Study. J Clin Oncol 2020;38:1580-90.

4. Aguilar EJ, Ricciuti B, Gainor JF, et al. Outcomes to first-line pembrolizumab in patients with non-small-cell lung cancer and very high PD-L1 expression. Ann Oncol 
2019;30:1653-9.

5. Hirsch FR, McElhinny A, Stanforth D, et al. PDL1 Immunohistochemistry Assays for Lung Cancer: Results from Phase 1 of the Blueprint PD-L1 IHC Assay Comparison Project. J Thorac Oncol 2017;12:208-22.

6. Topalian SL, Hodi FS, Brahmer JR, et al. Safety, Activity, and Immune Correlates of Anti-PD-1 Antibody in Cancer. N Engl J Med 2012;366:2443-54.

7. Shaverdian N, Lisberg AE, Bornazyan K, et al. Previous radiotherapy and the clinical activity and toxicity of pembrolizumab in the treatment of non-small-cell lung cancer: a secondary analysis of the KEYNOTE-001 phase 1 trial. Lancet Oncol 2017;18:895-903.

8. Mazieres J, Drilon A, Lusque A, et al. Immune checkpoint inhibitors for patients with advanced lung cancer and oncogenic driver alterations: results from the IMMUNOTARGET registry. Ann Oncol 2019;30:1321-8.

9. Garcia-Diaz A, Shin DS, Moreno BH, et al. Interferon Receptor Signaling Pathways Regulating PD-L1 and PDL2 Expression. Cell Rep 2017;19:1189-201.

10. Carbone DP, Reck M, Paz-Ares L, et al. First-Line Nivolumab in Stage IV or Recurrent Non-Small-Cell Lung Cancer. N Engl J Med 2017;376:2415-26.

11. Hellmann MD, Paz-Ares L, Bernabe Caro R, et al. Nivolumab plus Ipilimumab in Advanced Non-Small-Cell Lung Cancer. N Engl J Med 2019;381:2020-31.

12. Reck M, Rodríguez-Abreu D, Robinson AG, et al. Updated Analysis of KEYNOTE-024: Pembrolizumab Versus Platinum-Based Chemotherapy for Advanced NonSmall-Cell Lung Cancer With PD-L1 Tumor Proportion Score of 50\% or Greater. J Clin Oncol 2019;37:537-46.

13. Mok TSK, Wu YL, Kudaba I, et al. Pembrolizumab versus chemotherapy for previously untreated, PD-L1expressing, locally advanced or metastatic non-small-cell lung cancer (KEYNOTE-042): a randomised, open-label, controlled, phase 3 trial. Lancet 2019;393:1819-30.

14. Spigel D, de Marinis F, Giaccone G, et al. IMpower110: Interim overall survival (OS) analysis of a phase III study of atezolizumab (atezo) vs platinum-based chemotherapy (chemo) as first-line (1L) treatment (tx) in PD-L1-selected NSCLC. Ann Oncol 2019. doi: 10.1093/annonc/mdz293.

15. Gandhi L, Rodríguez-Abreu D, Gadgeel S, et al. Pembrolizumab plus Chemotherapy in Metastatic Non-Small-Cell Lung Cancer. N Engl J Med 2018;378:2078-92.

16. Gadgeel SM, Garassino MC, Esteban E, et al. KEYNOTE-189: Updated OS and progression after the next line of therapy (PFS2) with pembrolizumab (pembro) plus chemo with pemetrexed and platinum vs placebo plus chemo for metastatic nonsquamous NSCLC. J Clin Oncol 2019;37:9013.

17. Paz-Ares L, Luft A, Vicente D, et al. Pembrolizumab plus Chemotherapy for Squamous Non-Small-Cell Lung Cancer. N Engl J Med 2018;379:2040-51.

18. Ramalingam SS, Ciuleanu TE, Pluzanski A, et al. Nivolumab + ipilimumab versus platinum-doublet chemotherapy as first-line treatment for advanced nonsmall cell lung cancer: Three-year update from CheckMate 227 Part 1. J Clin Oncol 2020;38:9500.

19. Paz-Ares L, Spira A, Raben D, et al. Outcomes with durvalumab by tumour PD-L1 expression in unresectable, stage III non-small-cell lung cancer in the PACIFIC trial. Ann Oncol 2020;31:798-806.

20. Oaks MK, Hallett KM. Cutting edge: a soluble form of CTLA-4 in patients with autoimmune thyroid disease. J Immunol 2000;164:5015-8.

21. Zhu X, Lang J. Soluble PD-1 and PD-L1: predictive and prognostic significance in cancer. Oncotarget 2017;8:97671-82.

22. Frigola X, Inman BA, Krco CJ, et al. Soluble B7-H1: differences in production between dendritic cells and $\mathrm{T}$ cells. Immunol Lett 2012;142:78-82.

23. Chen Y, Wang Q, Shi B, et al. Development of a sandwich ELISA for evaluating soluble PD-L1 (CD274) in human sera of different ages as well as supernatants of PD-L1+ cell lines. Cytokine 2011;56:231-8.

24. Rossille D, Gressier M, Damotte D, et al. High level of soluble programmed cell death ligand 1 in blood impacts overall survival in aggressive diffuse large B-Cell lymphoma: results from a French multicenter clinical trial. Leukemia 2014;28:2367-75.

25. Costantini A, Julie C, Dumenil C, et al. Predictive role of plasmatic biomarkers in advanced non-small cell lung cancer treated by nivolumab. Oncoimmunology 2018;7:e1452581.

26. Zhang J, Gao J, Li Y, et al. Circulating PD-L1 in NSCLC patients and the correlation between the level of PD-L1 expression and the clinical characteristics. Thorac Cancer 2015;6:534-8.

27. Arrieta O, Montes-Servín E, Hernandez-Martinez JM, et al. Expression of PD-1/PD-L1 and PD-L2 in peripheral T-cells from non-small cell lung cancer patients. Oncotarget 2017;8:101994-2005.

28. Okuma Y, Hosomi Y, Nakahara Y, et al. High plasma levels of soluble programmed cell death ligand 1 are prognostic 
for reduced survival in advanced lung cancer. Lung Cancer 2017;104:1-6.

29. Ding Y, Sun C, Li J, et al. The Prognostic Significance of Soluble Programmed Death Ligand 1 Expression in Cancers: A Systematic Review and Meta-analysis. Scand J Immunol 2017;86:361-7.

30. Wei W, Xu B, Wang Y, et al. Prognostic significance of circulating soluble programmed death ligand-1 in patients with solid tumors: A meta-analysis. Medicine (Baltimore) 2018;97:e9617.

31. Tiako Meyo M, Jouinot A, Giroux-Leprieur E, et al. Predictive Value of Soluble PD-1, PD-L1, VEGFA, CD40 Ligand and CD44 for Nivolumab Therapy in Advanced Non-Small Cell Lung Cancer: A Case-Control Study. Cancers (Basel) 2020;12:473.

32. Okuma Y, Wakui H, Utsumi H, et al. Soluble Programmed Cell Death Ligand 1 as a Novel Biomarker for Nivolumab Therapy for Non-Small-cell Lung Cancer. Clin Lung Cancer 2018;19:410-417.e1.

33. Gong B, Kiyotani K, Sakata S, et al. Secreted PD-L1 variants mediate resistance to PD-L1 blockade therapy in non-small cell lung cancer. J Exp Med 2019;216:982-1000.

34. Kim DH, Kim H, Choi YJ, et al. Exosomal PD-L1 promotes tumor growth through immune escape in nonsmall cell lung cancer. Exp Mol Med 2019;51:1-13.

35. Chen G, Huang AC, Zhang W, et al. Exosomal PD-L1 contributes to immunosuppression and is associated with anti-PD-1 response. Nature 2018;560:382-6.

36. Chalmers ZR, Connelly CF, Fabrizio D, et al. Analysis of 100,000 human cancer genomes reveals the landscape of tumor mutational burden. Genome Med 2017;9:34.

37. Le DT, Durham JN, Smith KN, et al. Mismatch repair deficiency predicts response of solid tumors to PD-1 blockade. Science 2017;357:409-13.

38. Overman MJ, McDermott R, Leach JL, et al. Nivolumab in patients with metastatic DNA mismatch repair-deficient or microsatellite instability-high colorectal cancer (CheckMate 142): an open-label, multicentre, phase 2 study. Lancet Oncol 2017;18:1182-91.

39. Warth A, Körner S, Penzel R, et al. Microsatellite instability in pulmonary adenocarcinomas: a comprehensive study of 480 cases. Virchows Arch 2016;468:313-9.

40. Rizvi NA, Hellmann MD, Snyder A, et al. Mutational landscape determines sensitivity to PD-1 blockade in nonsmall cell lung cancer. Science 2015;348:124-8.

41. Alexandrov LB, Nik-Zainal S, Wedge DC, et al. Signatures of mutational processes in human cancer. Nature
2013;500:415-21.

42. Ricciuti B, Recondo G, Spurr LF, et al. Impact of DNA damage response and repair (DDR) gene mutations on efficacy of PD-(L)1 immune checkpoint inhibition in nonsmall cell lung cancer. Clin Cancer Res 2020;26:4135-42.

43. Turajlic S, Litchfield $\mathrm{K}, \mathrm{Xu} \mathrm{H}$, et al. Insertion-anddeletion-derived tumour-specific neoantigens and the immunogenic phenotype: a pan-cancer analysis. Lancet Oncol 2017;18:1009-21.

44. Hellmann MD, Ciuleanu TE, Pluzanski A, et al. Nivolumab plus Ipilimumab in Lung Cancer with a High Tumor Mutational Burden. N Engl J Med 2018;378:2093-104.

45. Paz-Ares L. Pembrolizumab (pembro) plus platinum-based chemotherapy (chemo) for metastatic nsclc: tissue tmb (ttmb) and outcomes in keynote-021, 189, and 407. ESMO 2019. Ann Oncol 2019;30:v851-v934.

46. Gandara DR, Kowanetz M, Mok TSK, et al. 1295OBloodbased biomarkers for cancer immunotherapy: Tumor mutational burden in blood (bTMB) is associated with improved atezolizumab (atezo) efficacy in 2L+ NSCLC (POPLAR and OAK). Ann Oncol 2017. doi: 10.1093/ annonc/mdx380.

47. Gandara DR, Paul SM, Kowanetz M, et al. Bloodbased tumor mutational burden as a predictor of clinical benefit in non-small-cell lung cancer patients treated with atezolizumab. Nat Med 2018;24:1441-8.

48. Rizvi NA, Chul Cho B, Reinmuth N, et al. Durvalumab with or without tremelimumab vs platinum-based chemotherapy as first-line treatment for metastatic non-small cell lung cancer: MYSTIC. Ann Oncol 2018;29:mdy511.005-mdy511.005.

49. Peters S, Cho BC, Reinmuth N, et al. Tumor mutational burden (TMB) as a biomarker of survival in metastatic non-small cell lung cancer (mNSCLC): Blood and tissue TMB analysis from MYSTIC, a Phase III study of firstline durvalumab \pm tremelimumab vs chemotherapy. Cancer Res 2019;79:CT074.

50. Socinski M, Velcheti V, Mekhail T, et al. Final efficacy results from B-F1RST, a prospective phase II trial evaluating blood-based tumour mutational burden (bTMB) as a predictive biomarker for atezolizumab (atezo) in 1L non-small cell lung cancer (NSCLC). Ann Oncol 2019. doi: 10.1093/annonc/mdz394.081.

51. Aggarwal C, Thompson JC, Chien AL, et al. Baseline plasma tumor mutation burden predicts response to pembrolizumab-based therapy in patients with metastatic non-small cell lung cancer. Clin Cancer Res 
2020;26:2354-61.

52. Available online: https://www.astrazeneca.com/mediacentre/press-releases/2019/update-on-the-phase-iiineptune-trial-of-imfinzi-plus-tremelimumab-in-stage-ivnon-small-cell-lung-cancer-21082019.html

53. Guisier F, Dubos-Arvis C, Viñas F, et al. Efficacy and safety of anti-PD-1 immunotherapy in patients with advanced Non Small Cell Lung Cancer with BRAF, HER2 or MET mutation or RET-translocation. GFPC 01-2018. J Thorac Oncol 2020;15:628-36.

54. Best SA, De Souza DP, Kersbergen A, et al. Synergy between the KEAP1/NRF2 and PI3K Pathways Drives Non-Small-Cell Lung Cancer with an Altered Immune Microenvironment. Cell Metab 2018;27:935-943.e4.

55. Skoulidis F, Arbour KC, Hellmann MD, et al. Association of STK11/LKB1 genomic alterations with lack of benefit from the addition of pembrolizumab to platinum doublet chemotherapy in non-squamous non-small cell lung cancer. J Clin Oncol 2019;37:102.

56. Rizvi NA. Mutations Associated with Sensitivity or Resistance to Immunotherapy in mNSCLC: Analysis from the MYSTIC Trial. WCLC 2019, Abstract OA0407.

57. Cho BC, Lopes G, Kowalski DM, et al. Relationship between STK11 and KEAP1 mutational status and efficacy in KEYNOTE-042: pembrolizumab monotherapy versus platinum-based chemotherapy as first-line therapy for PD-L1-positive advanced NSCLC. Cancer Res 2020;80:Abstract nr CT084.

58. Guibert N, Delaunay M, Lusque A, et al. PD-L1 expression in circulating tumor cells of advanced nonsmall cell lung cancer patients treated with nivolumab. Lung Cancer 2018;120:108-12.

59. Dhar M, Wong J, Che J, et al. Evaluation of PD-L1 expression on vortex-isolated circulating tumor cells in metastatic lung cancer. Sci Rep 2018;8:2592.

60. Goldberg SB, Narayan A, Kole AJ, et al. Early Assessment of Lung Cancer Immunotherapy Response via Circulating Tumor DNA. Clin Cancer Res 2018;24:1872-80.

61. Anagnostou V, Forde PM, White JR, et al. Dynamics of Tumor and Immune Responses during Immune Checkpoint Blockade in Non-Small Cell Lung Cancer. Cancer Res 2019;79:1214-25.

62. Cabel L, Riva F, Servois V, et al. Circulating tumor DNA changes for early monitoring of anti-PD1 immunotherapy: a proof-of-concept study. Ann Oncol 2017;28:1996-2001.

63. Guibert N, Jones G, Beeler JF, et al. Targeted sequencing of plasma cell-free DNA to predict response to PD1 inhibitors in advanced non-small cell lung cancer. Lung
Cancer 2019;137:1-6.

64. Nicolazzo C, Raimondi C, Mancini M, et al. Monitoring PD-L1 positive circulating tumor cells in non-small cell lung cancer patients treated with the PD-1 inhibitor Nivolumab. Sci Rep 2016;6:31726.

65. Janning M, Kobus F, Babayan A, et al. Determination of PD-L1 Expression in Circulating Tumor Cells of NSCLC Patients and Correlation with Response to PD-1/PD-L1 Inhibitors. Cancers (Basel) 2019;11:835.

66. Tamminga $M$, de Wit S, Hiltermann TJN, et al. Circulating tumor cells in advanced non-small cell lung cancer patients are associated with worse tumor response to checkpoint inhibitors. J Immunother Cancer 2019;7:173.

67. Duruisseaux M, Martínez-Cardús A, Calleja-Cervantes $\mathrm{ME}$, et al. Epigenetic prediction of response to anti-PD-1 treatment in non-small-cell lung cancer: a multicentre, retrospective analysis. Lancet Respir Med 2018;6:771-81.

68. Quail DF, Joyce JA. Microenvironmental regulation of tumor progression and metastasis. Nat Med 2013;19:1423-37.

69. Zitvogel L, Tesniere A, Kroemer G. Cancer despite immunosurveillance: immunoselection and immunosubversion. Nat Rev Immunol 2006;6:715-27.

70. Fridman WH, Pagès F, Sautès-Fridman C, Galon J. The immune contexture in human tumours: impact on clinical outcome. Nat Rev Cancer 2012;12:298-306.

71. Altorki NK, Markowitz GJ, Gao D, et al. The lung microenvironment: an important regulator of tumour growth and metastasis. Nat Rev Cancer 2019;19:9-31.

72. Brambilla E, Le Teuff G, Marguet S, et al. Prognostic Effect of Tumor Lymphocytic Infiltration in Resectable Non-Small-Cell Lung Cancer. J Clin Oncol 2016;34:1223-30.

73. Zeng DQ, Yu YF, Ou QY, et al. Prognostic and predictive value of tumor-infiltrating lymphocytes for clinical therapeutic research in patients with non-small cell lung cancer. Oncotarget 2016;7:13765-81.

74. Herbst RS, Soria JC, Kowanetz M, et al. Predictive correlates of response to the anti-PD-L1 antibody MPDL3280A in cancer patients. Nature 2014;515:563-7.

75. Sahba S, Niemeijer AL, De Langen J, et al. Association of tumor and stroma PD-1, PD-L1, CD3, CD4 and CD8 expression with response to nivolumab treatment in NSCLC patients. Ann Oncol 2017;28:107P.

76. Gataa I, Mezquita L, Auclin E, et al. Pathological evaluation of tumor infiltrating lymphocytes and the benefit of nivolumab in advanced non-small cell lung 
cancer (NSCLC). Ann Oncol 2017;28:112P.

77. Gettinger SN, Choi J, Mani N, et al. A dormant TIL phenotype defines non-small cell lung carcinomas sensitive to immune checkpoint blockers. Nat Commun 2018;9:3196.

78. Germain C, Gnjatic S, Tamzalit F, et al. Presence of B Cells in Tertiary Lymphoid Structures Is Associated with a Protective Immunity in Patients with Lung Cancer. Am J Respir Crit Care Med 2014;189:832-44.

79. Sautès-Fridman C, Petitprez F, Calderaro J, et al. Tertiary lymphoid structures in the era of cancer immunotherapy. Nat Rev Cancer 2019;19:307-25.

80. Cabrita R, Lauss M, Sanna A, et al. Tertiary lymphoid structures improve immunotherapy and survival in melanoma. Nature 2020;577:561-5.

81. Helmink BA, Reddy SM, Gao J, et al. B cells and tertiary lymphoid structures promote immunotherapy response. Nature 2020;577:549-55.

82. Petitprez F, de Reyniès A, Keung EZ, et al. B cells are associated with survival and immunotherapy response in sarcoma. Nature 2020;577:556-60.

83. Chen HY, Yu SL, Chen CH, et al. A five-gene signature and clinical outcome in non-small-cell lung cancer. N Engl J Med 2007;356:11-20.

84. Ayers M, Lunceford J, Nebozhyn M, et al. IFN- $\gamma$-related mRNA profile predicts clinical response to PD-1 blockade. J Clin Invest 2017;127:2930-40.

85. Prat A, Navarro A, Paré L, et al. Immune-Related Gene Expression Profiling After PD-1 Blockade in Non-Small Cell Lung Carcinoma, Head and Neck Squamous Cell Carcinoma, and Melanoma. Cancer Res 2017;77:3540-50.

86. Fehrenbacher L, Spira A, Ballinger M, et al. Atezolizumab versus docetaxel for patients with previously treated non-small-cell lung cancer (POPLAR): a multicentre, open-label, phase 2 randomised controlled trial. Lancet 2016;387:1837-46.

87. Karachaliou N, Gonzalez-Cao M, Crespo G, et al. Interferon gamma, an important marker of response to immune checkpoint blockade in non-small cell lung cancer and melanoma patients. Ther Adv Med Oncol 2018;10:1758834017749748.

88. Ivison S, Malek M, Garcia RV, et al. A standardized immune phenotyping and automated data analysis platform for multicenter biomarker studies. JCI Insight 2018;3:e121867.

89. Zheng H, Liu X, Zhang J, et al. Expression of PD-1 on CD4+ T cells in peripheral blood associates with poor clinical outcome in non-small cell lung cancer. Oncotarget
2016;7:56233-40.

90. Kamphorst AO, Pillai RN, Yang S, et al. Proliferation of PD-1+ CD8 T cells in peripheral blood after PD-1targeted therapy in lung cancer patients. Proc Natl Acad Sci 2017;114:4993-8.

91. Kim KH, Cho J, Ku BM, et al. The First-week Proliferative Response of Peripheral Blood PD-1 + CD8 + T Cells Predicts the Response to Anti-PD-1 Therapy in Solid Tumors. Clin Cancer Res 2019;25:2144-54.

92. Manjarrez-Orduño N, Menard LC, Kansal S, et al. Circulating T Cell Subpopulations Correlate With Immune Responses at the Tumor Site and Clinical Response to PD1 Inhibition in Non-Small Cell Lung Cancer. Front Immunol 2018;9:1613.

93. Zuazo M, Arasanz H, Fernández-Hinojal G, et al. Functional systemic CD4 immunity is required for clinical responses to PD-L1/PD-1 blockade therapy. EMBO Mol Med 2019;11:e10293.

94. Batliwalla FM, Rufer N, Lansdorp PM, et al. Oligoclonal expansions in the CD8(+)CD28(-) T cells largely explain the shorter telomeres detected in this subset: analysis by flow FISH. Hum Immunol 2000;61:951-8.

95. Bandrés E, Merino J, Vázquez B, et al. The increase of IFN-gamma production through aging correlates with the expanded CD8(+high)CD28(-)CD57(+) subpopulation. Clin Immunol 2000;96:230-5.

96. Ferrara R, Naigeon M, Auclin E, et al. Immunosenescence (iSenescence) correlates with disease progression in advanced non-small cell lung cancer (aNSCLC) patients treated with PD-(L)1 inhibitors (IO). Ann Oncol 2018;29:1416P.

97. Saavedra D, García B, Lorenzo-Luaces P, et al. Biomarkers related to immunosenescence: relationships with therapy and survival in lung cancer patients. Cancer Immunol Immunother CII 2016;65:37-45.

98. Donskov F. Immunomonitoring and prognostic relevance of neutrophils in clinical trials. Semin Cancer Biol 2013;23:200-7.

99. Kargl J, Busch SE, Yang GHY, et al. Neutrophils dominate the immune cell composition in non-small cell lung cancer. Nat Commun 2017;8:14381.

100. Charrier M, Mezquita L, Lueza B, et al. Circulating innate immune markers and outcomes in treatment-naïve advanced non-small cell lung cancer patients. Eur J Cancer 2019;108:88-96.

101.Jablonska J, Lang S, Sionov RV, et al. The regulation of pre-metastatic niche formation by neutrophils. Oncotarget 2017;8:112132-44. 
102. Templeton AJ, McNamara MG, Šeruga B, et al. Prognostic role of neutrophil-to-lymphocyte ratio in solid tumors: a systematic review and meta-analysis. J Natl Cancer Inst 2014;106:dju124.

103. Mezquita L, Auclin E, Ferrara R, et al. Association of the Lung Immune Prognostic Index With Immune Checkpoint Inhibitor Outcomes in Patients With Advanced Non-Small Cell Lung Cancer. JAMA Oncol 2018;4:351-7.

104. Sorich MJ, Rowland A, Karapetis CS, et al. Evaluation of the Lung Immune Prognostic Index for Prediction of Survival and Response in Patients Treated With Atezolizumab for NSCLC: Pooled Analysis of Clinical Trials. J Thorac Oncol 2019;14:1440-6.

105. Kazandjian D, Gong Y, Keegan P, et al. Prognostic Value of the Lung Immune Prognostic Index for Patients Treated for Metastatic Non-Small Cell Lung Cancer. JAMA Oncol 2019;5:1481-5.

106. Mezquita L, Auclin E, Besse B. Letter to the Editor about Sorich et al. J Thorac Oncol 2019;14:e209.

107. Mezquita L, Preeshagul I, Auclin E, et al. MA07.02 Early Change of dNLR Is Correlated with Outcomes in Advanced NSCLC Patients Treated with Immunotherapy. J Thorac Oncol 2019;14:S273.

108. Yamauchi Y, Safi S, Blattner C, et al. Circulating and Tumor Myeloid-derived Suppressor Cells in Resectable Non-Small Cell Lung Cancer. Am J Respir Crit Care Med 2018;198:777-87.

109. Liu CY, Wang YM, Wang CL, et al. Population alterations of L-arginase- and inducible nitric oxide synthaseexpressed CD11b+/CD14-/CD15+/CD33+ myeloidderived suppressor cells and CD8+ T lymphocytes in patients with advanced-stage non-small cell lung cancer. J Cancer Res Clin Oncol 2010;136:35-45.

110. Bronte V, Brandau S, Chen SH, et al. Recommendations for myeloid-derived suppressor cell nomenclature and characterization standards. Nat Commun 2016;7:12150.

111. Solito S, Marigo I, Pinton L, et al. Myeloid-derived suppressor cell heterogeneity in human cancers. Ann N Y Acad Sci 2014;1319:47-65.

112. Veglia F, Perego M, Gabrilovich D. Myeloidderived suppressor cells coming of age. Nat Immunol 2018;19:108-19.

113.Huang A, Zhang B, Wang B, et al. Increased CD14(+) HLA-DR (-/low) myeloid-derived suppressor cells correlate with extrathoracic metastasis and poor response to chemotherapy in non-small cell lung cancer patients. Cancer Immunol Immunother CII 2013;62:1439-51.
114. Vetsika EK, Koinis F, Gioulbasani M, et al. A circulating subpopulation of monocytic myeloid-derived suppressor cells as an independent prognostic/predictive factor in untreated non-small lung cancer patients. J Immunol Res 2014;2014:659294.

115.Kim HR, Park SM, Seo SU, et al. The Ratio of Peripheral Regulatory T Cells to Lox-1+ Polymorphonuclear Myeloid-derived Suppressor Cells Predicts the Early Response to Anti-PD-1 Therapy in Patients with NonSmall Cell Lung Cancer. Am J Respir Crit Care Med 2019;199:243-6.

116.Zhang J, Yao YH, Li BG, et al. Prognostic value of pretreatment serum lactate dehydrogenase level in patients with solid tumors: a systematic review and meta-analysis. Sci Rep 2015;5:9800.

117.Deng T, Zhang J, Meng Y, et al. Higher pretreatment lactate dehydrogenase concentration predicts worse overall survival in patients with lung cancer. Medicine (Baltimore) 2018;97:e12524.

118.Zhang Z, Li Y, Yan X, et al. Pretreatment lactate dehydrogenase may predict outcome of advanced non small-cell lung cancer patients treated with immune checkpoint inhibitors: A meta-analysis. Cancer Med 2019;8:1467-73.

119. Iivanainen S, Ahvonen J, Knuuttila A, et al. Elevated CRP levels indicate poor progression-free and overall survival on cancer patients treated with PD-1 inhibitors. ESMO Open 2019;4:e000531.

120. Oya Y, Yoshida T, Kuroda H, et al. Predictive clinical parameters for the response of nivolumab in pretreated advanced non-small-cell lung cancer. Oncotarget 2017;8:103117-28.

121. Shoji F, Takeoka H, Kozuma Y, et al. Pretreatment prognostic nutritional index as a novel biomarker in non-small cell lung cancer patients treated with immune checkpoint inhibitors. Lung Cancer 2019;136:45-51.

122. Sanmamed MF, Perez-Gracia JL, Schalper KA, et al. Changes in serum interleukin-8 (IL-8) levels reflect and predict response to anti-PD-1 treatment in melanoma and non-small-cell lung cancer patients. Ann Oncol 2017;28:1988-95.

123. Boutsikou E, Domvri K, Hardavella G, et al. Tumour necrosis factor, interferon-gamma and interleukins as predictive markers of antiprogrammed cell-death protein-1 treatment in advanced non-small cell lung cancer: a pragmatic approach in clinical practice. Ther Adv Med Oncol 2018;10:1758835918768238.

124. Sivan A, Corrales L, Hubert N, et al. Commensal 
Bifidobacterium promotes antitumor immunity and facilitates anti-PD-L1 efficacy. Science 2015;350:1084-9.

125. Gopalakrishnan V, Spencer CN, Nezi L, et al. Gut microbiome modulates response to anti-PD-1 immunotherapy in melanoma patients. Science 2018;359:97-103.

126.Jin Y, Dong H, Xia L, et al. The Diversity of Gut Microbiome is Associated With Favorable Responses to Anti-Programmed Death 1 Immunotherapy in Chinese

Cite this article as: Duchemann B, Remon J, Naigeon $M$, Cassard L, Jouniaux JM, Boselli L, Grivel J, Auclin E, Desnoyer A, Besse B, Chaput N. Current and future biomarkers for outcomes with immunotherapy in non-small cell lung cancer. Transl Lung Cancer Res 2021;10(6):2937-2954. doi: 10.21037/ tlcr-20-839
Patients With NSCLC. J Thorac Oncol 2019;14:1378-89. 127. Routy B, Le Chatelier E, Derosa L, et al. Gut microbiome influences efficacy of PD-1-based immunotherapy against epithelial tumors. Science 2018;359:91-7.

128. Hakozaki T, Richard C, Elkrief A, et al. The gut microbiome associates with immune checkpoint inhibition outcomes in patients with advanced non-small cell lung cancer. Cancer Immunol Res 2020;8:1243-50. 